JQCJC VOLUME 8 ISSUE 3 (SPRING 2020)

\title{
WHAT'S AFTER GOOD?: THE BURDEN OF POST-INCARCERATION LIFE
}

\author{
Quintin Williams ${ }^{1}$ \\ Loyola University Chicago \\ Cesraéa Rumpf \\ Benedictine University
}

\begin{abstract}
In the current era of mass incarceration, an increasing number of people face the challenge of transitioning from prison to society. Researchers of post-incarceration life have produced a detailed account of the collateral consequences of incarceration, noting the numerous barriers people must overcome as they try to return to society. In this paper, we show how stigma continues to be a structuring force in the lives of the formerly incarcerated. We develop the concept of the burden of post-incarceration life, meaning the structural constraints formerly incarcerated people face and the constant work they undertake to demonstrate and attempt to receive recognition for their rehabilitation. We argue that this burden is a critical though understudied aspect of life after prison. To develop this argument, we draw upon ethnographic and qualitative interview data from two distinct research projects with formerly incarcerated men and women in Chicago and highlight three interrelated themes that emerged from our data: judgment, exploitation, and competing demands. By centering burden in our analysis, we conclude that a focus on overcoming barriers may obfuscate the ongoing challenges formerly incarcerated people face.
\end{abstract}

Keywords: reentry, rehabilitation, stigma, burden

\section{INTRODUCTION}

One consequence of mass incarceration is that an increasing number of people must navigate the reentry process. As Travis (2009) notes, each year more than 700,000 people leave state and federal prisons, and more than nine million individuals leave jails, representing what Petersilia (2003) identifies as "[o]ne of the most profound challenges facing American society"

\footnotetext{
${ }^{1}$ Correspondence regarding this article should be addressed to Quintin Williams, Department of Sociology, Loyola University Chicago, 1032 W. Sheridan Road, Chicago, IL 60660, qwilliams@luc.edu. We extend our sincerest appreciation to Jodie Dewey, Edward Orozco Flores, Timothy O'Brien, Gwendolyn Purifoye, and Megan Welsh for their insightful feedback on earlier drafts of the paper. We thank the anonymous peer reviewers and editor for their critical feedback, which greatly strengthened this paper. We also are thankful for research assistance provided by Flannery Bohne, Andrea Gurga, Hannah Ramlo, and Paul Tran at Loyola University Chicago. Funding from the Arthur J. Schmitt Foundation and The Graduate School at Loyola University Chicago made research contributing to this article possible. Both studies received IRB approval from Loyola University Chicago.
} 
(p. 3). Of particular concern to scholars who study post-incarceration experiences is that the majority of people released from prison will be arrested post-release, and many will return to prison (Travis, Solomon, and Waul, 2001). These scholars detail many barriers that limit formerly incarcerated people's ability to establish housing, employment, financial stability, and family relationships and that even contribute to reincarceration (e.g., Alexander, 2010; Geller and Curtis, 2011; Leverentz, 2014; Middlemass, 2017; Pager, 2007; Petersilia, 2003; Richie, 2001; Sered and Norton-Hawk, 2014; Travis, 2009). They also consistently show the positive impact education, employment, and prosocial relationships have in formerly incarcerated people's lives (e.g., Laub and Sampson, 2001).

In addition to post-incarceration barriers, a growing body of qualitative scholarship details the ongoing work formerly incarcerated people engage in to distance their current selves from their past selves. Often employing a symbolic-interaction perspective, this research examines how formerly incarcerated people come to think of themselves as rehabilitated and seek to earn recognition of that rehabilitation (Giordano, Cernkovich, \& Rudolph, 2002; Harris 2011; Leverentz 2014; Maruna, 2001; Opsal, 2011; Opsal, 2012). In his influential book Making Good: How Ex-Convicts Reform and Rebuild Their Lives, Maruna (2001) identifies a commonality in the narratives "desisting ex-offenders" tell about their lives: "They recast their criminal pasts not as the shameful failings that they are but instead as the necessary prelude to some newfound calling" (p. 9). In other words, they change their thinking not only about their past, but also about their current identities and behavior. Maruna (2001) refers to this "process of willful, cognitive distortion as "making good"' (p. 9). Internal identity changes are just as important as overcoming external barriers to employment, housing, and other positive social attachments. Furthermore, these internal and external changes are interrelated, as accomplishments such as securing employment can encourage positive shifts in one's conception of self and vice versa (Harris, 2011; Leverentz, 2014; Opsal, 2012).

Together, this scholarship on barriers and identity makes clear that post-incarceration experiences are deeply challenging and even disorienting. Yet, whether intentional or not, this scholarship often implies that once people have overcome reentry barriers and established rehabilitated identities, their lives are indeed changed, and reentry is, in some sense, complete ${ }^{2}$.

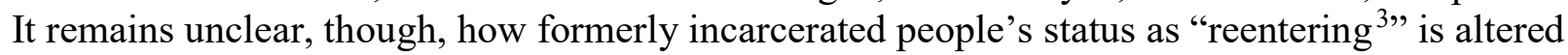
once they lay hold to social supports. Said another way, what happens to people after they "make good" (Maruna 2001), that is once they have made an obvious investment both materially and internally to becoming something other than the criminal label? Our findings reveal that "making good" (Maruna, 2001) is not the end of the story. Challenges exist long after barriers have been removed and together encapsulate the totality of post-incarceration life.

In this paper, we encourage scholars studying post-incarceration experiences to move beyond a barrier framework and instead prioritize burden, which we argue exists even when people with records accomplish all of the typical markers of "successful reentry." Seeking to understand the qualitative, everyday nature of post-incarceration life, we ask how do formerly incarcerated people experience life after prison or jail, what is the daily work people do to

\footnotetext{
${ }^{2}$ McCorkel's (2013), Miller's (2016), and Sered and Norton-Hawk's (2014) work are notable exceptions that describe reentry and recovery as lifelong processes.

${ }^{3}$ We view "reentry" and "reintegration" as inaccurate terms since most incarcerated people did not experience social inclusion prior to their criminalization due to intersecting oppressions such as racism, sexism, and poverty (Bumiller, 2013; Wacquant, 2010). We thus use less concise but more accurate terms like post-incarceration experiences throughout the paper. When we use "reentry," we place it in quotes to reference its widespread use within scholarship on post-incarceration life.
} 
manage this new and oftentimes permanent change in social status, and how does this work impact people, particularly when there is no guarantee it will be validated. To answer these questions, we bring together data from two separate qualitative research projects with formerly incarcerated people in Chicago. Our research questions direct our attention to Goffman's (1963) theorizing on stigma and what Welsh and Rajah (2014) have termed the "work of reentry." We examine this work and offer the concept of the burden of post-incarceration life, which refers to the constraints formerly incarcerated people face in addition to the constant work they undertake to demonstrate and attempt to receive recognition for their rehabilitation and to combat stigma. By doing so, we highlight the multi-layered impact of post-incarceration life. We center our analysis on three shared, interrelated themes that emerged across our data - judgment, exploitation, and competing demands - and then show how these themes intersect in people's lives to illustrate our concept of burden. We conclude that this burden is a structuring force in formerly incarcerated people's lives that persists despite policy reforms designed to ease the "reentry" process.

\section{THE FAR-REACHING IMPACT OF INCARCERATION}

The research on collateral consequences, meaning the intended and unintended negative sanctions resulting from a criminal conviction, documents the extensive barriers criminalized people face (Mauer and Chesney-Lind, 2002). There are an estimated 48,000 collateral consequences for returning citizens in the United States (NICC, 2018). Mauer and Chesney-Lind (2002) argue that these punishments are hidden or "invisible" because the damage incurred happens well beyond the initial sentence. People with felony convictions may lose a host of social welfare benefits, including food stamps and public housing, and face discrimination in employment and the private housing market (Finzen, 2005). These consequences are embedded in racial inequalities (Alexander, 2010; Middlemass, 2017; Wheelock, 2005). In her examination of employment outcomes of people with felony convictions, Pager (2007) found that Black men without a felony conviction fared no better than white men with a felony conviction, clearly illustrating how the "negative credential" (p. 32) of a felony conviction is preceded by the mark that is race. These two variables compounded make for very unfavorable circumstances for individuals who have both "marks" (Pager, 2007, p. 116). Race and criminal conviction similarly limit women's experiences in the labor market. Gurusami's research (2017) reveals how parole officers pressure formerly incarcerated Black women to secure jobs the state will recognize as legitimate and as signs of moral rehabilitation, thereby pushing women into low-paying, unstable work. The racial and gender inequity of the labor market collide with a criminal record and state surveillance to relegate criminalized Black women to permanent low-income status. Moreover, the marks of race, gender, and criminal conviction ensure harmful employment-related consequences are spatially concentrated, having impacts not only at the individual level but also community-wide (Pattillo, Weiman, and Western, 2004; see also La Vigne et al., 2003; Richie, 2001).

In addition to the impact on economic security and housing, felony convictions in many states lead to the loss of parental rights, the right to vote, and other civic engagement opportunities, such as the right to serve on a jury (Olivares and Burton, 1996). The loss of voting 
privileges has impacted important elections (Uggen and Manza, 2002) and raised questions about whether these "neo-civil death" (Smiley, 2014) practices are new forms of Jim Crow era policy (Alexander, 2010). Additional noted collateral consequences include mass incarceration's generational impact (Western and Petitt, 2010) and parental incarceration's impact on children and families (Turanovic, Rodriguez, and Pratt, 2012). At the time of their incarceration, women are more likely than men to be parents of minor children and to be the sole caretaker of those children (National Research Council, 2014). This reality introduces an additional set of gendered collateral consequences related to reunification with children and surveillance by Child Protective Services (Leverentz, 2014; Richie, 2001; Sered and Norton-Hawk, 2014; Welsh and Rajah, 2014). Furthermore, formerly incarcerated women face a lack of gender-specific resources, as many "reentry" programs focus on men (Richie, 2001).

The collateral consequences literature elucidates the harsh realities of returning home and highlights the myriad barriers people face long after their sentence ends. However, we know less about what happens once barriers are overcome and people achieve outward markers of success, such as employment and civic engagement. As we demonstrate below, for the participants in our research, the burden remains even after barriers diminish. Collateral consequences are indeed "invisible" (Mauer and Chesney-Lind, 2002), but we suggest a focus on burden reveals yet another layer of invisibility.

\section{The Promise and Limits of Social Control}

A major contribution of the collateral consequences literature has been to document the way formerly incarcerated people systematically are denied the very supports that help end involvement with the criminal legal system. Researchers using a social control perspective show that attachments to conventional social institutions, such as marriage and employment, gradually exert a constraining influence on behavior over time and encourage desistance (Giordano et al., 2002; Hirschi 1969; Sampson and Laub, 1992). As individuals plug into traditional mechanisms of normality and feel a part of mainstream culture, they have more to lose and thus refrain from participating in criminalized behaviors. Research on post-incarceration employment affirms the social control perspective, showing that employment provides much more than just an income. It also can provide a sense of purpose and affirmation that an individual is a contributing member of society, as well as guard against becoming discouraged in the desistance process (Leverentz, 2014; Opsal, 2012; Uggen, 1999). An examination by Bahr et al. (2009) of what differentiates so-called successful and unsuccessful parole outcomes provides further support for the social control perspective. They found that people on parole who did not exhibit behaviors associated with participation in crime (e.g., rearrest, substance use) within three years had completed substance abuse programs in prison, worked at least 40 hours per week, and spent time with friends. In sum, positive attachments to institutions and prosocial relationships exert significant influence over post-incarceration life.

When talking about social controls, it is important also to consider the ways inequalities may shape social attachments and how bonds or social controls may be experienced differently for those who are socially positioned differently. Save a few examples (see Apel, 2016; Doherty and Bersani, 2016; Uggen, 1999), there are noteworthy limitations to the social control perspective, however. For one, it does not always pay adequate attention to the ways social inequalities, particularly related to race, class, and gender, limit the positive impact social attachments have. For instance, employment does not guarantee financial security. Lichtenberger 
(2006) found that even when formerly incarcerated people obtained employment, it was confined to specific sectors such as manufacturing, construction, and food services. Conversely, people with felony convictions were grossly underrepresented in jobs with higher pay, such as those in the information industry, finance, and scientific and technical services fields. Bumiller (2013) and Purser (2012) show how formerly incarcerated people often are relegated to the most marginal types of employment within the expanded precarious employment sector of the postindustrial U.S. economy. Employers of "bad jobs," such as day labor agencies, rely on men and women who have felony convictions and thus cannot find employment elsewhere to fulfill contracted employers' orders for laborers and even forge relationships with reentry service providers to facilitate access to desperate and disenfranchised workers (Bumiller, 2013; Purser, 2012). As such, the institutions that shape post-incarceration life and try to respond to collateral consequences actually can perpetuate and even exacerbate marginalization. Over time, the inability to secure employment and frustration with the poor quality jobs that are available can undermine desistance efforts (Harris, 2011; Leverentz, 2014; Opsal, 2012).

\section{Cognitive Transformations, Replacement Selves, and Making Good}

While the social control perspective identifies specific factors that facilitate desistance processes, it does not explain how and in what ways individuals arrive at these social controls or maintain them. Scholarship on identity transformation begins to address this gap. Rooted in the symbolic-interaction tradition, this scholarship focuses more closely on the role of individual agency in the desistance process and examines people's efforts to distance themselves from their past criminalized identities and establish rehabilitated identities (Adorjan and Chui, 2012; Giordano et al., 2002; Harris, 2011; Leverentz, 2014; Maruna, 2001; Opsal, 2011; Opsal, 2012). Giordano et al. (2002) examine the "“up front' work" (p. 992) formerly incarcerated people do to change their lives even before encountering potentially helpful social controls. Their cognitive transformation theory centers the role of people in creatively and selectively appropriating elements in the environment, like prosocial relationships, employment, and services that support desistance (Giordano et al., 2002; see also Haggard et al., 2001; Harris, 2011; Opsal, 2012; Teti et al., 2011). In short, the availability of potentially helpful social controls will have limited impact if people are not ready to change.

Maruna's (2001) examination of the narratives formerly incarcerated people tell about their lives significantly deepens understandings of how cognitive transformation occurs. Maruna (2001) suggests that desistance happens via a cognitive reframing of past criminal activity and maintenance of a new positive self. These replacement selves begin to influence individuals' actions and can motivate ongoing change even in the absence of support and resources. Formal reentry programs have taken up this focus on creating new, rehabilitated identities. Miller (2016), for one, conceptualizes reentry as a social institution with "generative capacities" in which "reentry programs facilitate a space for new social forms to emerge, 'making up' the ex-offender as particular kind of person" (p. 32). Using ethnographic data from groups he observed at a Chicago reentry home for men, Miller (2016) examines two processes that facilitate personal transformation: "the will to be transformed," demonstrated by sharing personal failings and being open to others' feedback and critiques, and "the will to transform," demonstrated by 
mentoring and correcting others who offer excuses for their personal failings, such as pointing to structural inequalities and discrimination (p. 22). The ongoing work of personal reflection and correcting others facilitates a successful performance of rehabilitation (Miller, 2016). Flores and Cossyleon (2017) also note the importance of receiving recognition of one's rehabilitated identity. They conclude one reason participants are interested in faith-based community organizing is because it "afforded them precious space to demonstrate being reformed" (Flores and Cossyleon, 2017, p. 13). These studies show that rehabilitation is an interactive accomplishment that depends on others recognizing a criminalized individual as reformed.

\section{Stigma and the Never-ending Work of Reentry}

Recent qualitative scholarship on the mental and emotional labor of post-incarceration life supplements the literature on legal discrimination based on felony convictions and identity transformation, as discussed above (e.g., Leverentz, 2014; Middlemass, 2017; Sered and NortonHawk, 2014; Welsh and Rajah, 2014). Welsh and Rajah's (2014) concept of "reentry work" (p. 326) provides a useful unifying framework for these studies. Reentry work includes the daily physical, mental, and emotional work formerly incarcerated people undertake to meet institutional requirements, such as those imposed by parole and public aid, and to take care of themselves, such as securing housing and reestablishing family relationships (Welsh and Rajah, 2014). Importantly, state agents and service providers do not recognize all of these activities as work. A parole officer, for instance, may focus primarily on whether someone has secured paid employment and thereby discount the equally taxing work of looking for housing, coordinating transportation, or piecing together childcare arrangements. Formerly incarcerated people, particularly women, devote much time and energy to work the state does not recognize, which exacerbates the stress of post-incarceration life.

When state agents fail to recognize the multiple types of work formerly incarcerated people do, they subject people to competing institutional demands and impossible decisions, such as whether to meet with one's parole officer or go to a required appointment to maintain welfare eligibility (Welsh and Rajah, 2014, p. 329; see also Richie, 2001). Furthermore, they overlook the daily strain that characterizes formerly incarcerated people's lives. Even when someone has attained housing or employment, the continuous work of reentry and of demonstrating a rehabilitated identity can undercut these outward markers of success.

The literature on stigma offers helpful insights as to why reentry work and identity transformation are such demanding, long-term processes. Goffman (1963) argues that despite a stigmatized individual's efforts to "correct what he sees as the objective basis of his failing... what often results is not the acquisition of fully normal status, but a transformation of self from someone with a particular blemish into someone with a record of having corrected a particular blemish" (p. 9). It follows then that while the salience of the criminal label may wane, the stigma of that label will persist, regardless of the corrective actions formerly incarcerated people take to overcome it. Link and Phelan (2001) explain that stigma emerges "when elements of labeling, stereotyping, separation, status loss, and discrimination co-occur in a power situation that allows the components of stigma to unfold" (p. 367). This attention to power elucidates how stigma is interactional and structural. Focusing on structural discrimination, Link and Phelan (2001) show how stigma impacts all areas of a person's life, even when one cannot point to an explicit, individual act of discrimination. They conclude, "Stigma has affected the structure around the person, leading the person to be exposed to a host of untoward circumstances" (Link 
and Phelan, 2001, p. 373). This conceptualization of stigma aptly describes the numerous challenges formerly incarcerated people face. The collateral consequences delineated above follow from the stigma of the criminal label that marks formerly incarcerated people as different, dangerous, and unworthy and thus justifies discrimination (Uggen, Manza, and Behrens, 2004). The criminal legal system administers a process of ongoing stigmatization, what John Braithwaite (1989) terms "disintegrative shaming in which no effort is made to reconcile the offender with the community. The offender is outcast, her deviance is allowed to become a master status, degradation ceremonies are not followed by ceremonies to decertify deviance" ( $p$. 101). Even after completing their sentence, criminalized people are denied "acquisition of the fully normal status" (Goffman, 1963, p. 9).

Goffman's (1963) and Link and Phelan's (2001) conceptualization of stigma are instructive for examining stigma's totalizing impact on formerly incarcerated people's lives. We seek to understand how the pervasive impact of stigma structures people's overall lives. In addition to the obvious barriers people encounter based on a criminal conviction, it is important to understand the cumulative impact of these barriers and the intangible ways that labeling and discrimination shape the very nature of formerly incarcerated people's lives. It also is important to examine how formerly incarcerated people understand these experiences, but "there is a paucity of literature on formerly incarcerated persons' perceptions of stigma" (LeBel, 2012, p. 90).

\section{THE BURDEN OF POST-INCARCERATION LIFE}

For the remainder of this paper, we build upon Goffman's (1963) theorizing about stigma and Welsh and Rajah's (2014) concept of "reentry work" to examine what we term the burden of post-incarceration life. Like other qualitative researchers, we draw attention to the cumulative burden formerly incarcerated people shoulder as they encounter collateral consequences, navigate competing institutional demands, and perform rehabilitation. We go beyond acknowledgment, though, and argue that this burden is a structuring force in criminalized people's lives. The burden of post-incarceration life refers to the constant work formerly incarcerated people undertake to demonstrate their rehabilitation, the stress caused by the uncertainty of whether others will recognize their rehabilitation, and the routine demands of meeting material needs and planning for the future. In short, the burden of post-incarceration life encapsulates the stress of structural discrimination and of having to constantly perform redemption. It also indicates the permanent nature of post-incarceration life. Repairing stigma does not mean a "fully normal status" is achieved (Goffman, 1963, p. 9). As such, overcoming barriers does not end the stigma of criminalization; burden persists. 
Table 1. Conceptualizing the Burden of Post-Incarceration Life

\begin{tabular}{|c|c|c|}
\hline Collateral Consequences & Stigma & Work of Reentry \\
\hline $\begin{array}{ll}\text { - } & \text { Housing } \\
\text { discrimination } \\
\text { - } & \text { Employment } \\
\text { discrimination } \\
\text { - } \\
\text { Voting rights } \\
\text { restrictions } \\
\text { - Loss of parental } \\
\text { rights } \\
\text { - Licensing } \\
\text { exclusions }\end{array}$ & $\begin{array}{l}\text { - The "mark" of a } \\
\text { criminal record } \\
\text { - Discreditable } \\
\text { social status } \\
\text { - Offense category }\end{array}$ & $\begin{array}{ll}\text { - } & \text { Constant } \\
\text { performance of } \\
\text { rehabilitated status } \\
\text { - Unrecognized work } \\
\text { - } & \text { Navigation of } \\
\text { multiple social } \\
\text { service entities }\end{array}$ \\
\hline
\end{tabular}

To develop our argument about burden, we draw upon the first author's ethnographic research with Fighting to Overcome Records and Create Equality (FORCE), a faith-based communityorganizing group led by formerly incarcerated people in Chicago, and the second author's research with formerly incarcerated women in Chicago. Bringing our research together demonstrates the value of shifting from a barrier to a burden framework to investigate the challenges of post-incarceration life.

\section{METHODS}

The data for this paper come from two distinct research projects conducted independently by each author. Each project investigated how people manage life after release from prison. Williams investigated this process from the standpoint of formerly incarcerated people who are engaged in organizing and advocacy. This project combined two and a half years of participant observations with 16 semi-structured interviews with FORCE members between January 2013 and June 2015. Each interview lasted between forty-five minutes to an hour. Participants were not compensated for participation in the study. Williams took field notes in meetings and public events, thereby developing a strong rapport with group members. This was in part due to being upfront about his support and position regarding some of the group's issues. In addition to the role of researcher, Williams spoke at events describing campaigns and helped in training sessions. The level of participation varied depending on the situation. In meetings, Williams answered questions and gave input when asked. Becoming this immersed allowed him to see the process of community organizing in detail, which helped with understanding the overall political/strategic process in which FORCE was involved. His involvement was consistent with the view that carrying out core functions and tasks, "provides special opportunities to get close to, participate in, and experience life in previously unknown settings" (Emerson, Fretz, and Shaw, 1995, p. 4). Most importantly, he was able to develop an understanding of the realities of life after prison as FORCE members fought for rights, as well as the work they did to participate in the fight. Williams transcribed the interviews and field notes. Field notes were typed within 24-48 hours of leaving the field. 
Rumpf's project examined how women understood and responded to their experiences of criminalization, incarceration, and post-incarceration. Rumpf used a combination of in-depth semi-structured qualitative interviews and participant-generated photo-elicitation interviews (PEI). Participant-generated PEI involves providing participants with cameras to take photographs that will help them tell their stories. The photographs become the basis of a subsequent interview, during which the participant selects the photographs she wishes to discuss in the order she wants to discuss them and explains what each image communicates. In addition to producing richer data than can qualitative interviews alone, PEI also helps to disrupt the inherent power differential between researcher and participant (Frohmann, 2005; Rumpf 2017).

Rumpf worked with two recovery homes and one non-residential program to recruit participants. She completed 99 interviews with 36 women between December 2012 and July 2013. Thirty-two participants completed a PEI. Interviews focused broadly on women's experiences leading to their involvement with the criminal legal system, their incarceration, and their lives since release. During the interviews, Rumpf asked women to reflect on the challenges they faced, as well as sources of support. Each interview typically lasted between an hour and a half and two hours. Participants received a \$20 gift card to the store of their choosing for each interview session and kept the digital cameras they received to complete the PEI. Interviews were audio-recorded and transcribed.

Consistent with the literature on incarceration and post-incarceration, the majority of participants in both studies are people of color who face severe economic constraints. Although half of the participants across both studies had some form of cash income, amounts usually were quite low, totaling less than $\$ 1000$ per month. Often, these incomes were not stable, as some participants' employment was part-time and/or seasonal. More participants in Williams's study were employed than participants in Rumpf's study, which likely reflects Williams's recruitment of participants through FORCE, where many participants were employed. Across both studies, the majority of participants are parents and age 40 or older, with a mean age of 44 and a median age of 44.5 .

Table 2. Participants' Demographics

\begin{tabular}{llccc}
\hline & & $\begin{array}{c}\text { Author 1 } \\
(\mathrm{N}=16)\end{array}$ & $\begin{array}{c}\text { Author 2* } \\
(\mathrm{N}=36)\end{array}$ & $\begin{array}{c}\text { Total } \\
(\mathrm{N}=52)\end{array}$ \\
\hline Gender & Men & 13 & 0 & 13 \\
& Women & 3 & 36 & 39 \\
Age & Range & $22-64$ & $20-63$ & $20-64$ \\
& Mean & 40.9 & 45.5 & 44 \\
& Median & 39.5 & 46.5 & 44.5 \\
& & & & \\
Race & & & & 39 \\
& Black/African Am. & 10 & 29 & 7 \\
& White & 3 & 4 & 3 \\
& Multi-racial & 1 & 1 & 3
\end{tabular}




\begin{tabular}{llccc} 
Employment & Not employed & 2 & 24 & 26 \\
& Employed & 14 & 12 & 26 \\
Income & None & 2 & 1 & 3 \\
& Food stamps only & 0 & 15 & 15 \\
& Some cash & 14 & 12 & 26 \\
Parent & & & & \\
& Yes & 16 & 31 & 47 \\
\hline
\end{tabular}

*For categories that do not total 36, some participants did not provide corresponding information.

We each took a grounded theory approach (Charmaz, 2006) in coding our data for our initial, independent projects. In coding interview transcripts and field notes, Williams did an initial round of open coding in order to reveal patterns and trends and also counters to those trends. He then created several conceptual categories that focused on processes that enabled or constrained participants' community organizing. From these categories, Williams began to construct theoretical memos that lead to the development of the concept the redemption imperative. In coding interview transcripts, Rumpf initially paid close attention to discussions about violence, surveillance, denial of assistance, and support. As her coding progressed, recovery from drug use and rehabilitation of one's identity emerged as two primary, interconnected themes. Through memoing, Rumpf clarified the connections between these themes, primarily how drug use was related to the violence women experienced and led to women's incarceration. Recovery from drug use was a centerpiece of women's work not only to end their involvement with the criminal legal system, but also to construct positive self-identities that would demonstrate their overall rehabilitation, facilitate access to resources, and help with re-establishing relationships with family members, particularly their children.

In sharing our findings, we were struck by the strong parallels between the ways participants in each study discussed their post-incarceration experiences. ${ }^{4}$ Despite using different recruitment and data collection methods and thus working with two very different populations, the focus on redemption and the at times overwhelming strain of post-incarceration life emerged as a primary finding across our two projects and proved to be complementary in addressing the research questions for this article: how do formerly incarcerated people experience life after prison or jail, what is the daily work people do to manage this new and often permanent change in social status, and how does this work impact people, particularly when there is no guarantee it will be validated? In both settings we examined formerly incarcerated people trying to "make good" (Maruna, 2001) and the ambivalence this process entails. As some research participants had attained traditional markers of successful "reentry," we began to ask, what happens after people "make good" (Maruna, 2001). Employment, housing, educational degrees, and program completion were not the end of the story. We combined individual work with group meetings that facilitated the exchange of interpretations and the construction of the hermeneutic and analytic body of the paper. Through our discussions, we began to think about post-incarceration

\footnotetext{
${ }^{4}$ There were noteworthy differences, such as a focus on recovery from drug use in the women's interviews and a general lack of attention to this topic among FORCE members. This difference likely resulted from the different missions of our recruitment sites and well-documented differences in gendered pathways to incarceration. A fuller examination of these differences is beyond the scope of this paper, as what is striking are the similarities that emerged.
} 
as an ongoing burden. We each returned to our data and coded interviews and field notes for examples of burden, paying attention to the ways participants spoke about burden and how they defined and made sense of it. From there, we brought together patterns of similarities in meanings across the data to identify shared themes of strain, burden, and work, while also attentive to exceptions to these patterns, or "negative cases" (Glaser and Strauss, 1967). As we began writing analytic memos and descriptions of empirical findings, judgment, exploitation, and competing demands emerged as three of the clearest and most compelling illustrations of burden. By putting our independent projects in conversation with one another, we are uniquely positioned to speak to some unseen consequences of incarceration and begin to paint a picture of how stigma structures post-incarceration life while formerly incarcerated people continuously work to prove their redemption.

\section{FINDINGS}

In this section, we identify and explain three shared themes that emerged from our projects and illustrate the burden of post-incarceration life: judgment, exploitation, and competing demands. These interrelated themes reinforce one another and cumulatively contribute to the overarching burden participants shouldered, even as they achieved outward markers of success, such as securing employment, completing programs, and deepening their involvement with organizing efforts. Additionally, each theme highlights how participants had to engage with the ongoing work of performing redemption. The examples we provide below are representative of themes that emerged across interviews and field encounters with multiple participants. Every interview participant expressed at least one specific experience of judgment, exploitation, or competing demands.

\section{Judgment}

Participants' experiences of being judged by others because of their criminalization was a common theme that emerged across both studies. Nearly every interview participant (92\%) discussed this theme ${ }^{5}$. Judgment spanned institutional and community settings and often surprised participants.

Judgment from Institutions. Participants in both studies were denied employment solely due to past criminal convictions. For instance, Angel $^{6}$, a 38-year-old Latino man, recalled a painful experience of being judged by a potential employer. During his undergraduate studies, he had begun working for a department at his university. He explained:

\footnotetext{
${ }^{5}$ Where we present percentages related to the prevalence of themes, we calculate these percentages based on 49 interview participants (13 participants in Williams's study and 36 participants in Rumpf's study). Three of the 16 interview participants in Williams's study were allies who were not FORCE members; we therefore based our calculations on 49 rather than 52 interview participants.

${ }^{6}$ Participants' names are pseudonyms. Participants in Rumpf's study chose their pseudonym.
} 
I was working for free for three months till one day...my boss calls me, and you could tell that he was disappointed and upset and he says, "Angel, I am sorry I wasn't able to hire you." He apologized a hundred times, and I don't blame him, he is a good person. I blame the policies that were in place...he told me it was my background is what stopped you from getting a job. Part of me, I was like, "I don't give a shit." I got a job anyway, and I learned through that process. I was training, doing research, and being a community liaison, as well, but after I hung up, I cried 'cause at that moment, I told myself, "I am one month away from getting my bachelors of social work, just got accepted to [a graduate program at a prestigious university], I have spoken at the United Nations, and have spoken at every university in Chicago...started all these different programs," but because of my record it stopped me from getting this part-time job...I did feel defeated at that moment.

Angel was surprised and hurt by the rescinded job offer, especially since he felt he already had proved himself to his employer and had overcome the "mark" of the criminal record (Pager, 2007). By the time of this incident, Angel had become a recognized organizer and advocate not only throughout Chicago but even on an international stage. His unexpected dismissal interrupted his current progress and forced him to question the viability of his educational and career goals and whether the identities associated with those goals truly were attainable. The university's decision was a harsh reminder that regardless of how hard he worked or how much he achieved, his status as a rehabilitated person always could be called into question, and others' judgments could undercut his hard work ${ }^{7}$. Consequently, Angel grappled with the realization that even after he earns educational degrees and secures paid employment, he will have to continue the work of performing his rehabilitation indefinitely, with the knowledge that his performed rehabilitation may never be sufficient to achieve stability.

The ongoing threat of judgment also came across in an interview with Olivia, a 49-yearold Afro-American woman ${ }^{8}$. Like Angel, Olivia had been a clear example of a post-incarceration success story. She had been out of prison for about six years, employed full-time at Growing Stronger ${ }^{9}$, a recovery home where she once had been a resident, and earning about $\$ 1400$ per month. She had completed her GED and had her own apartment. By most outward measures of success, Olivia was doing quite well. At the time of her final interview with Rumpf, however, she was struggling. She recently had been fired from her job after residents and at least one coworker reported to Olivia's boss that she had come to work while high. With no job and no income, she quickly was going through her savings. She stressed that her supervisors had no proof she had been high; they had not been at the recovery home that day, nor had they made her take a drug test. Rumpf did not try to ascertain whether Olivia was using drugs again or had shown up to work while under the influence. Rather, what was telling about Olivia's experience was just how fragile her successful rehabilitation, employment, and overall "reentry" had been. Olivia's credibility about her sobriety could be called into question rather easily, regardless of whether she had used drugs, precisely because of her identity as a "recovering addict" and an

\footnotetext{
${ }^{7}$ In her research with formerly incarcerated women in Chicago, Leverentz (2014) similarly found that "women began to see limitations in the value of education or college degrees, as their criminal records often still trumped these credentials" (p. 154).

${ }^{8}$ Rumpf uses the terms participants provided to identify their own race.

9 This organization's name is a pseudonym.
} 
"ex-offender." Despite her accomplishments and status as a role model to the Growing Stronger residents, she remained vulnerable to others' judgments.

Together, Angel's and Olivia's experiences expand our understanding of the precarious employment to which many formerly incarcerated people are relegated. Scholarship on postincarceration employment focuses on its exploitive nature, highlighting important concerns such as low pay, instability, harmful working conditions, lack of upward mobility, coercion, and increased surveillance (Bumiller, 2013; Gurusami, 2017; Purser, 2012). Angel and Olivia arguably had found jobs situated higher in the labor market hierarchy than the low-wage service work documented in much of the extant literature that should have offered a degree of stability and, beyond a consistent paycheck, a sense of meaning and purpose in their work. For both, however, their felony convictions cemented the tenuous nature of their employment. They remained vulnerable to the seemingly unpredictable "policies that were in place" that at any time could upend the fleeting security they had felt. Moreover, these policies resulted in more than losing or being denied a job, which is what a barrier framework would highlight. Shifting to a burden framework helps us understand how vulnerability regarding employment persists over time and in ways that impact the very sense of self Angel and Olivia constructed through their previous reentry work.

Judgment from Communities. Participants in both studies shared experiences of being judged in less likely settings, such as by community and church members. Jose, a 38-year-old Latino man, gave an example of how his community was "quick to pass judgment." He recalled:

When I was doing a lot of outreach, people would see me...talking to troubled youth and say, "I thought you change your life," and I would just be like, "I am doing my job," and they would say, "Oh, they are paying you to be a gang member now." People used to see me talking to these troubled youths... and they would call me a hypocrite.

Jose was securely employed and trying to better his community by preventing other young men from following the same path to prison he had followed. As Flores and Cossyleon (2014) also found in their research with FORCE members, working to "give back to youth" was a key "element of...redemption scripts" (p. 9). Yet, even when Jose was practicing and modeling redemption, community members suspected he was not truly rehabilitated. As Goffman (1963) theorized, Jose's corrective actions did not result in the "acquisition of fully normal status" (p. 9). His past identity remains in conflict with whom he is trying to be, as Jose remains marginalized within his community.

The inescapable judgment Jose experienced from community members mirrored the cold reception Chicken Wing, a 55-year-old Black woman, received when trying to find a church to attend regularly. After serving 21 years in prison, Chicken Wing remained under correctional supervision and, as part of her parole conditions, wore an electronic monitor on her ankle at all times. She explained that people looked down on her, even in church: "Even my boyfriend, he do not want me to go to his church and show this [the electronic monitor]. He want me to wear pants. Because people will look at me funny...That's wrong! That ain't right...That's wrong! You don't judge people." The electronic monitor publicly marked Chicken Wing as a criminal, 
subverting her efforts to communicate her rehabilitation and cementing her stigmatized identity. Even in an environment that ostensibly should have been welcoming and inclusive, Chicken Wing was acutely aware of how others viewed and judged her. The message was clear: she did not belong. The ongoing stigma she faced and the separation it created from community members introduced additional stress into her life (Goffman, 1963; Link and Phelan, 2001). Social control perspectives suggest that a romantic relationship and church involvement would act as stabilizing forces in Chicken Wing's life (Hirschi, 1969; Sampson and Laub, 1992). These social attachments were insufficient, though, to overcome the stigmatized criminal label. The literal mark she had to wear subverted that impact and forced her to engage the additional work of coming to terms with her boyfriend's reaction and finding a more welcoming church.

These examples illustrate the impact of judgment in participants' lives and how it originated from an array of sources. Even when participants were doing rather well navigating the transition from prison to society, the mark of the criminal record and subsequent judgment remained. This judgment emerged unexpectedly at times, even in moments when individuals were demonstrating their rehabilitated identities, thereby contributing to the overarching burden of post-incarceration life. As such, judgment undermined people's engagement with the very social controls that are predictors of "successful reentry" and caused considerable stress as participants attempted to engage these supports. If researchers fail to capture these deeper collateral consequences tied to the intense stigma of the criminal label, we inadvertently will miss this meaningful aspect of the post-incarceration experience. Shifting to a burden framework foregrounds these deep and long-lasting impacts of stigma.

\section{Exploitation}

Exploitation was a second shared theme that emerged across our two studies, with at least one-third of participants discussing a specific example. Participants' concerns about exploitation were tied to the underlying threat of being judged. The criminal label exposed people to judgment, which in turn left them open to exploitation. Reggie, a 50-year-old Black man and FORCE member, explained how searching for housing was not only demoralizing but also expensive:

It is already a struggle to find a job, and then you have to struggle to get an apartment...I got tricked outta so much money, security this, fee this, just to be told I couldn't get it because of my background, and that should have been the first thing they told me [before] they took my money.

Reggie pointed to layers of burden, as his felony conviction exposed him to two well-known collateral consequences: legally, employers and housing providers could discriminate against him. Thus, with severely limited funds and a lack of viable housing options, Reggie was desperate for housing. Discrimination and desperation made him an easy target for landlords who gladly would collect an application fee or security deposit from him, only to inform him that he was not eligible to live in their building because of his felony conviction. Not only did Reggie face the stress of finding housing, but he also had to ascertain which landlords he could trust not to exploit him by collecting fees when they had no intention of renting to him. All of this was even though Reggie regularly attended his church, worked multiple jobs, and did community organizing and advocacy work in his limited spare time. 
Moon, a 40-year-old African-American woman, similarly reflected on the stress and frustration of gauging which service providers and programs genuinely assist people. She criticized job-readiness programs that do not connect people to actual employment. Plenty of programs provide a certificate of completion, free meals, clothing referrals, and other supports that, in Moon's assessment, do not make a difference. She concluded that the only people who genuinely benefit from these types of programs are the people who run them:

When the class over, they come hand you a certificate that you can't do nothin' with. But they still get a paycheck because you was there, you see...I don't want to be a part of that...If I go somewhere, I want a job... What you told me when I came through these doors you was gonna do for me, that's what I want...I don't want you to keep gettin' these grants just because.

Moon continued, explaining how she thought job readiness programs intentionally trick people into signing up with them. According to her, program administrators think:

"We'll get 'em all in here. We'll hire one [former program participant], so they'll know that, yeah, she's seen her in prison, so now she sees her here with this suit on"...We knew her from prison, [so we think], "Oh yeah, we will go there! They'll hire us too." When the thing was over with, they, you didn't have no job, you get this certificate...They send you to this place... get you a really nice outfit, that's your trinkets, like what they tricked the slaves with, that's your trinkets, to make you feel like, "Oh yeah, we really gonna get a job now." Then, when it's over with, nobody get a job... all you got is a piece of paper that don't mean shit to nobody, you know?

Like Reggie, Moon resented how people who were better off than she was and whose very jobs were to assist her instead viewed her as a source of income and used her, with no concern for her wellbeing. Jerry, a 40-year-old Black man, explained being used in a similar way:

Jerry: One thing I tell people to be careful of, when people see you are a good volunteer they will make empty promises. They say, "I will get you a job," and they would string you along.

QW: Was that your experience?

Jerry: Yeah, I experienced that a few times in a few places. For me they didn't understand it's not about if you get me a job. I am doing this as long as I want to because [I] want to, and you saying you gone get me a job ain't gone keep me no longer than I'ma stay.

Here Jerry describes telling people to be cautious in their volunteerism because of the potential of being taken advantage of. Like Moon, he has learned how nonprofits and other organizations can potentially capitalize on the tenuous employment prospects of people with records. While Jerry perceived this exploitation and resisted, the attempt is telling in that it underscores the 
vulnerability that criminalized people face even while working toward positive community service. Furthermore, this finding deepens our understanding of "the synergistic relations among prisons, the reintegration industry, social services, and the labour market" (Bumiller, 2013, p. 74). In addition to day labor agencies recruiting workers from reentry programs and the threat of reincarceration compelling people on parole to accept degrading employment, Jerry and Moon reveal how social service programs benefit from formerly incarcerated people's relegation to the "precarious proletariat" class (Purser, 2012, p. 13).

These three examples point to the burden of post-incarceration life, which goes beyond collateral consequences and persists even when formerly incarcerated people are working to demonstrate their commitment to becoming full members of society. Similar to the judgments participants faced, their vulnerability to exploitation further relegated them to the margins of society. Even more telling, their connection to helping organizations obscured their marginalization. Reggie, Moon, and Jerry were plugged into support networks, yet behind their outward makers of success lay concerns about and actual experiences of exploitation that limited their progress. This undercurrent of concern maps on to the persistent judgment of stigmatized identities noted above to create a pervasive burden associated with the criminal label that is not reducible to individual barriers.

\section{Competing Demands}

One of the strongest shared themes that emerged across our data was the physical, emotional, and mental toll of managing post-incarceration life. Almost every participant alluded to ongoing challenges they encountered and the unfaltering perseverance they must show in the face of these challenges. A subset of participants, nearly one-quarter, recalled specific instances when it was not possible to fulfill various demands on their time and the resulting stress they experienced. As scholars who study women's post-incarceration experiences have noted, the multitude of institutions to which women are accountable can impose overwhelming demands (e.g., Leverentz, 2014; Richie, 2001; Welsh and Rajah, 2014). Trying to follow the requirements of parole, Child Protective Services, drug treatment programs, and reentry homes can make women feel like they are in an impossible situation and will never be able to please everyone. Ranisha, a 34-year-old Black woman, vividly captured this feeling with a photograph she had taken of herself flipping off the camera. While discussing the image, Ranisha explained what had been going on that day:

Those one of the days I was bein' bombarded with all the, go here, go there, go, and I had to start makin' choices of, “Okay I can't do this 'cause I gotta do this today," and when I called the DCFS [Department of Children and Family Services] worker to let her know, it was like, "Well, you gotta do time management." Time management? You know, I have groups here [at the recovery home], I have to go to outside groups, and then, you know, so I had wind up missin' a few classes...And she [the DCFS caseworker] tried to like chastise me for it, and I was lettin' her know there ain't no way in hell you can do that, because if the lady tell me to come to domestic violence at 11 o'clock and I have IOP [intensive outpatient treatment for substance abuse] and don't get out 'til 12, you know, it don't do me no good to go to IOP' cause I'm not gonna get credit. 
Similar to Welsh and Rajah's (2014) finding of formerly incarcerated women facing institutional demands that not only are overwhelming but conflict such that women cannot accomplish all of them, Ranisha was exasperated by the DCFS caseworker's suggestion to work on her time management skills. Time management would neither create more hours in the day nor change the conflicting times of mandated classes and groups. Failing to meet these requirements, however, could lead to termination of parental rights, revocation of probation, and being asked to leave the recovery home. Ranisha faced an impossible choice.

A second photograph Ranisha took for her PEI underscored just how overwhelming these competing institutional demands were. The photograph was another one Ranisha had taken of herself, but this one showed her smiling at the camera on what she called a "good day" when she was about to leave the recovery home on a weekend pass to stay with her boyfriend. She reflected:

I be excited to go home, because I get a chance to relax... and it's like no gettin' up at seven in the mornin'...no group...it's just like a day that I can actually just sit back and know that I don't have to get up and do anything. You know, I could lay and think. I could read a book if I want to...I just feel comfortable...lay in the bed with him and just be held, because that's what I think I be missin' sometimes. You know, just wanna be held sometimes...makes me feel good to know that this is what I'm goin' to.

Ranisha recalled a peaceful weekend morning with her boyfriend that starkly contrasted with the rigid schedule she had to follow and the surveillance she experienced during the week. She had been able to feel like a full person, worthy of needs and desires, rather than a case to be managed, and she welcomed the brief respite from the burden of continuously having to prove her rehabilitation.

Ironically, individuals' successes, such as employment, school enrollment, and assuming responsibilities with reentry programs, at times, created more stress as they struggled to manage the competing demands on their time. Williams found that while participants welcomed increased advocacy and organizing opportunities with FORCE, becoming more involved with the organization could conflict with other obligations. Reggie, who was employed painting houses, had to rearrange his work schedule in order to participate in FORCE activities.

Reggie: But sometimes I will work on the weekends and make up the lil' hours, but sometimes the hours can make a difference.

QW: Can you tell me about a time when this happened?

Reggie: Yeah. I went to Springfield [to do advocacy work with FORCE] one time on a Tuesday, and a house was supposed to be painted by Thursday, and I spent all that time on the bus, and I ended up having to work 12 hours when I got back to finish the job.

QW: Is that something that has happened on a regular basis since you have been involved with FORCE?

Reggie: Yeah. It has happened at least two or three times when it conflicted with 
my work schedule, sometimes it be too complicated. I will have [a friend] come and give me a hand.

Similarly, Frank, a 40-year-old Black man, reflected on how FORCE activities had conflicted with his schoolwork, prompting him to renegotiate his role with the organization.

Frank: I'm like, "I'm in school right now. I might wanna take a step back and do some conference calls or something like that because my commute is like three hours." I don't drive or anything like that. I just kinda like streamline my stuff the way I need to do to get through...my main goals.

QW: And what are those main goals?

Frank: To graduate with my master's degree, to continue, and they are somewhat intertwined, I wanna do social justice, it's just the time commitment of FORCE is just, but back to my goals, be a father, repair my relationship with my kids, and this is a lot of time-intensive slow work that I am totally willing to do. I am totally capable of doing all of these other commitments. Sometimes I get a little bit overwhelmed.

Like Reggie, Frank showed that while he embraced and enjoyed taking on additional responsibilities and meeting commitments that were important to him, doing so introduced an additional source of stress. Giving back through organizing with FORCE was a priority for both men and part of the redemption imperative (Williams, 2015). It allowed them to demonstrate their rehabilitation and make a positive difference in their communities. Additionally, it added another requirement to a list of already competing demands and the subsequent stress of trying to do it all or deciding which responsibilities to let go. Even when those demands were welcomed opportunities, choosing where to focus one's energy and assessing whether there would be negative consequences of passing on opportunities proved difficult.

\section{How Burden Develops}

The burden of post-incarceration life denotes the cumulative experience that encompasses collateral consequences, stigma, and the work of reentry. Scholars often examine these dimensions of post-incarceration experiences as individual barriers to overcome and propose policy recommendations that would lessen the impact of each barrier. However, none of these dimensions alone can explain the totality of the post-incarceration experience. These challenges, in our view, are better explained from a burden perspective rather than a barrier perspective. While we have presented examples above of judgment, exploitation, and competing demands, it is not the number of examples but rather the overall, stifling nature of the post-incarceration experience that emerged as the most compelling finding from our two projects. Examining how the above-noted themes of judgment, exploitation, and competing demands interact demonstrates the value of the burden perspective. For instance, in Ranisha's situation, the stress she felt from trying to manage the competing demands imposed by DCFS, parole, and the recovery home was exacerbated by the judgment she faced from each and the significant power each wielded over her. If she cannot manage the competing demands, her DCFS caseworker may judge her to be an unfit mother and move to terminate her parental rights, or her parole officer may judge her to be not serious about her recovery and move to revoke her parole. A focus on barriers overlooks the 
unique threats and stress produced at the intersection of judgment and competing demands.

Table 3. Impacts of the Burden of Post-Incarceration Life

\begin{tabular}{|c|c|c|}
\hline Judgment & Exploitation & Competing Demands \\
\hline $\begin{array}{l}\text { - Questioned } \\
\text { credibility of } \\
\text { sobriety } \\
\text { - Challenges to } \\
\text { reformed status } \\
\text { - } \text { Denial of } \\
\text { employment } \\
\text { despite credentials } \\
\text { - Stigma within } \\
\text { community } \\
\text { institutions }\end{array}$ & $\begin{array}{l}\text { - Fees for rental } \\
\text { applications taken } \\
\text { in bad faith } \\
\text { - Free labor } \\
\text { - Job readiness } \\
\text { programs not } \\
\text { helping individuals }\end{array}$ & $\begin{array}{l}\text { - Complex } \\
\text { bureaucratic } \\
\text { systems that do not } \\
\text { talk to each other } \\
\text { - Work hours } \\
\text { incompatible with } \\
\text { performance of } \\
\text { rehabilitation } \\
\text { - Entangled in } \\
\text { multiple legal } \\
\text { systems }\end{array}$ \\
\hline
\end{tabular}

Two additional examples illustrate how the above-noted themes interact to produce a post-incarceration burden that can overwhelm participants. Over time, the lack of resources and support, the persistent judgment, and the threat and actual instances of exploitation wore people down. In some cases, participants who initially had been quite optimistic about rebuilding their lives ended up feeling rather pessimistic about the likelihood of attaining their goals. Rumpf noticed a marked change in Moon's demeanor between their first and third interviews. When she commented on this observation, Moon explained:

The euphoria wears off. See...bein' in prison is like you... in slavery, a modern day slavery, or you bound. So...in your mind, you be feelin' like anything better than this place [prison]. Then, when you get to this place [the recovery home], and you been here for a lil' bit, the euphoria wears off, because, see, in prison you just wanna be free. When you actually get out here to freedom, the euphoria of havin' a place to be, that wears off, because now you thinkin' like the next level, how I'm gonna get there, because I'm stagnated, because I don't have a job, and then... you get to know the people, the mask comes off...then you see where you really at, you don't wanna be there... a lot of women here, when they first get here, they all happy and stuff like that, but then the real life part kicks in. You see...things for what they really are [as] opposed to how they come off at first, and you just want out, you know? You just, you know, you want better for yourself.

Moon's description of the initial "euphoria" of being released from prison echoed what Frank described as the "I'm on fire moment." He elaborated: 
When people first come out, there is a special moment in time when people...if they made the decision that they wanna do right and get going, they can really be used. You can work with them and can get a lot out of them, the community, organizations, whoever. We call that the "I'm on fire moment," and that was my thing.

That moment could be crucial in helping people find the stamina and determination to meet the competing demands of post-incarceration life, withstand others' judgments of their character and worthiness for services, and continuously demonstrate their rehabilitation. For some, however, the demands became overwhelming; when their efforts did not lead to employment, housing, reunification with children, or the attainment of other important goals, the initial optimism and fire could fade.

These examples illustrate perhaps most clearly our concept of the burden of postincarceration life and its value over using a barrier perspective. The cumulative impact of struggling daily to meet one's basic needs and to be recognized as a rehabilitated person capable of contributing to society was a significant part of participants' post-incarceration experiences that resulted from more than a list of barriers they had to overcome. By highlighting the day-today experiences of the formerly incarcerated, we see the path one must take on the road to redemption: a road without an endpoint that is rife with very real but often unseen challenges that only an in-depth examination could reveal.

\section{DISCUSSION}

If we are serious about supporting criminalized people in their efforts to transition back to society, then we must listen to formerly incarcerated people. We must understand what they truly are up against and develop strategies that offer meaningful support. In this paper, we have strived to contribute to the reentry literature by focusing on the qualitative everyday lived experiences of post-incarceration life. Building upon other qualitative investigations that highlight the "work of reentry" (Welsh and Rajah, 2014), we have shown that a focus on barriers not only is incomplete but actually may obfuscate the ongoing challenges formerly incarcerated people face, particularly after they "make good" (Maruna, 2001).

There is a fundamental difference in stating the barriers of post-incarceration life versus the burden of post-incarceration life, as the two frameworks underscore different issues. To be clear, barriers are part of what creates burden; however, making them analytically distinct is useful in a few ways. One way the burden framework advances our understanding of postincarceration challenges is that burden does not assume that formerly incarcerated people face minimal or no challenges once barriers (e.g., employment, housing, drug use) are overcome. Second, this framework has policy implications regarding implementation. For instance, if we pass laws that prohibit asking about a criminal record, how might we follow up to ensure that this practice happens and lessens the burden that the barrier may have caused? Reggie and Moon suggest it is not enough to attain employment, as individuals must also show a constant euphoric drive and fire to better themselves. Last, a burden approach forces us to look deeper into the ways we can further humanize this dehumanized population. Focusing on the everyday experiences of burden takes us deeper into the lives of the formerly incarcerated to see how their longings, aspirations, and challenges fundamentally are human and are not merely characterized by (in)ability to engage in positive prosocial activities. 
Burden is a structuring force in formerly incarcerated people's lives and therefore must be engaged more fully by scholars. The mark of the criminal record looms large and subjects formerly incarcerated people to judgment and exploitation, which undercut even their most dedicated efforts to navigate post-incarceration life. Despite impressive accomplishments and unwavering determination, participants still had to fight against suspicions that they were not truly reformed. Achievements were, at times, no match for the weight of their past, which was physically and psychologically ever present and often cast a shadow of doubt over any achievements. Indeed, both authors concluded their studies with the sense that the work of "reentry" and redemption never would be complete.

This paper also reveals potential avenues for further research that is outside of the scope of the findings presented here. For instance, it was not readily clear in our data how race, class, and place may mediate the experiences of the post-incarceration burden. We suspect that different class standing and location of residence pre- and post-incarceration may shield some from the impact of a criminal record. Similarly, it is fair to ask if criminalized people who are white experience this burden in the same way as Black and Latinx persons with records do. Also, our data do not clearly show if the type of crime matters in experiencing the post-incarceration burden. Is this burden lessened if a person has a conviction for a white-collar crime versus a street crime? Uncovering differences in burden could add substantial depth to our understanding of post-incarceration experiences. However, before we can learn the differences in burden, we must prioritize burden as a conceptual framework to deepen our understanding of everyday experiences. Lastly, in this paper, we have made clear that reentry is not merely a process, transition, or period of time; rather, the burden of incarceration is a more permanent state. Thus, future research should consider that post-incarceration life is not time-limited and therefore look at the long-term consequences of incarceration, not just the more common year or few years post-release.

\section{CONCLUSION}

The burden of post-incarceration life concept encapsulates the totality of the postincarceration experience and suggests the limitations of many reform efforts that focus on removing individual barriers. Even if employment is secured, housing is attained, voting rights are restored, and schooling is accessible, burden creates a precarious undercurrent that keeps criminalized people destabilized and vulnerable to actions that will undermine financial and housing security, as well as the carefully crafted sense of a rehabilitated self. As Link and Phelan (2001) argue regarding efforts to decrease stigma, "any approach must be multifaceted and multilevel. It needs to be multifaceted to address the many mechanisms that can lead to disadvantaged outcomes, and it needs to be multilevel to address issues of both individual and structural discrimination. But second, and most important, an approach to change must ultimately address the fundamental cause of stigma" (p. 381). Engaging burden raises questions about how we can create new policies and practices that reclaim the humanity of formerly incarcerated people and facilitate genuine social inclusion (Braithwaite, 1989; Maruna, 2011). In other words, how do we remove the stigma associated with a criminal conviction?

With the imposition of a criminal conviction, our society commits to punishing people 
forever. As our research shows, that punishment has a totalizing impact on people's lives, even after completion of the formal sentence and even after people "make good" (Maruna, 2001). Thus, we must develop policies that disrupt this punitive hold and address its totalizing impact. Criminal justice and public policy reforms focused solely on expungement and eliminating collateral consequences do not go far enough. This is not to say such reform efforts should not be pursued. We support advocacy and organizing work that seeks legislative and policy changes to benefit criminalized people, such as efforts to end life without parole and mandatory minimum sentencing and make those decisions retroactive, restore funding for higher education in prison, reinstate parole at the federal level and in all states, ban the box on job and college applications, and prevent housing discrimination based on criminal conviction. Removing the barriers people face following incarceration may indeed lessen the burden they experience. But, as we have documented here, there is something deeper about the criminal label and its associated stigma that sets people with criminal records apart from society. Even with the removal of barriers, the burden of post-incarceration life will remain until our society removes the stigma that permanently shapes formerly incarcerated people's lives.

Foregrounding a burden perspective suggests some immediate practical changes reentry programs could make in their efforts to help formerly incarcerated people. For one, job training and job placement services are insufficient in terms of employment assistance. Reentry organizations could train employers not only to hire people with felony convictions but also to be more inclusive and accommodating. Through public outreach and education efforts, reentry organizations could work to radically transform employers', educators', landlords', and the wider public's view of what a criminal record means. Coupled with widespread efforts to remove reentry barriers, such work could begin to decrease the stigma of the criminal label and the associated burden of post-incarceration life.

\section{REFERENCES}

Adorjan, M. \& Chui, H.W. (2012). Making sense of going straight. British Journal of Criminology, 52(3), 577-590.

Alexander, M. (2010). The new Jim Crow: Mass incarceration in the age of colorblindness. New York, NY: The New Press.

Apel, R. (2016). The effects of jail and prison confinement on cohabitation and marriage. The Annals of the American Academy of Political and Social Science, 665(1), 103-126.

Bahr, S., Harris, L., Fisher, J., \& Armstrong, A. (2009). Successful reentry: What differentiates successful and unsuccessful parolees? International Journal of Offender Therapy and Comparative Criminology, 54(5), 667-692.

Braithwaite, J. (1989). Crime, shame, and reintegration. New York, NY: Cambridge University Press. 
Bumiller, K. (2013). Incarceration, welfare state and labour market nexus: The increasing significance of gender in the prison system. In B. Carlton \& M. Segrave (Eds.), Critical Essays on Gender, Post-Release Support and Survival (pp. 52-93). New York, NY: Routledge.

Charmaz, K. (2006). Constructing grounded theory: A practical guide through qualitative analysis. Thousand Oaks, CA: SAGE Publications Inc.

Doherty, E. E., \& Bersani, B. E. (2016). Understanding the mechanisms of desistance at the intersections of race, gender, and neighborhood context. Journal of Research in Crime and Delinquency, 53(5), 681-710.

Emerson, R. M., Fretz, R. I., \& Shaw, L. L. (1995). Writing ethnographic fieldnotes. Chicago, IL: The University of Chicago Press.

Finzen, M. (2005). Systems of oppression: The collateral consequences of incarceration and their effects on black communities. Georgetown Journal on Poverty Law \& Policy, 12(2), 299324.

Flores, E. O., \& Cossyleon, J. E. (2017). "I went through it so you don't have to": Faith-based community organizing for the formerly incarcerated. Journal for the Scientific Study of Religion, Advance online publication. DOI: 10.1111/jssr.12294.

Frohmann, L. (2005). The framing safety project: Photographs and narratives by battered women. Violence Against Women, 11(11), 1396-1419.

Geller, A., \& Curtis, M. A. (2011). A sort of homecoming: Incarceration and the housing security of urban men. Social Science Research, 40(4), 1196-1213.

Giordano, P. C., Cernkovich, S.A., \& Rudolph, J.L. (2002). Gender, crime, and desistance: Toward a theory of cognitive transformation. American Journal of Sociology, 107(4), 990-1064.

Glaser, B. G., \& Strauss, A. L. (1967). The discovery of grounded theory: Strategies for qualitative research. Chicago, IL: Aldine.

Goffman, E. (1963). Stigma: Notes on the management of spoiled identity. New York, NY: Simon and Schuster.

Gurusami, S. (2017). Working for redemption: Formerly incarcerated black women and punishment in the labor market. Gender \& Society, 31(4), 433-456. 
Haggard, U., Gumpert, C.H., \& Grann, M. (2001). Against all odds: A qualitative follow-up study of high-risk violent offenders who were not reconvicted. Journal Of Interpersonal Violence, 16(10), 1048-1065.

Halushka, J. (2016). Managing rehabilitation: Negotiating performance accountability at the frontlines of reentry service provision. Punishment \& Society. Advance online publication. DOI: 10.1177/1462474516669356.

Harris, A. (2011). Constructing clean dreams: Accounts, future selves, and social and structural support as desistance work. Symbolic Interaction, 34(1), 63-85.

Hirschi, T. (1969). Causes of Delinquency. Berkeley, CA: University of California Press.

Laub, J. H. \& Sampson, R. J. (2001). “Understanding desistance from crime.” Crime and Justice, 28, 1-69.

La Vigne, N. G., Mamalian, C. A., Travis, J., and Visher, C. (2003). A portrait of prisoner reentry in Illinois. Washington, DC: The Urban Institute.

LeBel, T. P. (2012). Invisible stripes? Formerly incarcerated persons' perceptions of stigma. Deviant Behavior, 33, 89-107.

Leverentz, A. M. (2014). The ex-prisoner's dilemma: How women negotiate competing narratives of reentry and desistance. New Brunswick, NJ: Rutgers University Press.

Lichtenberger, E. (2006). Where do ex-offenders find jobs? An industrial profile of the employers of ex-offenders in Virginia. The Journal of Correctional Education, 57(4), 297-311.

Link, B. G. \& Phelan, J. C. (2001). Conceptualizing stigma.” Annual Review of Sociology, 27, 363-385.

Lynch, M. (2000). Rehabilitation as rhetoric: The ideal of reformation in contemporary parole discourse and practices. Punishment \& Society, 2(1), 40-65.

Maruna, S. (2001). Making good: How ex-convicts reform and rebuild theirlLives. Washington, DC: American Psychological Association.

Maruna, S. (2011). Reentry as a rite of passage. Punishment \& Society, 13(1), 3-28.

Mauer, M. \& Chesney-Lind, M. (2002). Invisible punishment: The collateral consequences of mass imprisonment. New York, NY: The New Press.

McCorkel J.A. (2013). Breaking women: Gender, race, and the new politics of imprisonment. New York, NY: New York University Press. 
Middlemass, K. M. (2017). Convicted and condemned: The politics and policies of prisoner reentry. New York, NY: New York University Press.

Miller, R. J. (2014). Devolving the carceral state: Race, prisoner reentry, and the micro-politics of urban poverty management. Punishment \& Society, 16(3), 305-335.

Miller, R.J. (2016). "You're in a room full of addicts!' Prisoner reentry as a social institution and the making up of the ex-offender." School of Social Work, University of Michigan. Unpublished manuscript.

National Research Council. (2014). The growth of incarceration in the United States: Exploring causes and consequences. Washington, DC: The National Academies Press.

National Inventory of Collateral Consequences. (2018). Retrieved May 29, 2018 (https://niccc.csgjusticecenter.org/)

Olivares, K. M., Burton Jr., V. S., \& Cullen, F. T. (1996). The collateral consequences of a felony conviction: A national study of state legal codes 10 years later. Federal Probation, 60(3), 10-17.

Opsal, T. (2011). Women disrupting a marginalized identity: Subverting the parolee identity through narrative. Journal of Contemporary Ethnography (40)2, 135-167.

Opsal, T. (2012). "Livin' on the straights": Identity, desistance, and work among women postincarceration. Sociological Inquiry, 82(3), 378-403.

Pager, D. (2007). Marked: Race, crime, and finding work in an era of mass incarceration. Chicago, IL: University of Chicago Press.

Pattillo, M., Weiman, D., \& Western, B. (Eds.). (2004). Imprisoning America: The social effects of mass incarceration. New York, NY: Russell Sage Foundation.

Petersilia, J. (2003). When prisoners come home: Parole and prisoner reentry. Oxford: Oxford University Press.

Purser, G. (2012). The labour of liminality. LABOUR, Capital and Society, 45(1), 11-35.

Richie, B. E. (2001). Challenges incarcerated women face as they return to their communities: Findings from life history interviews. Crime \& Delinquency, 47(3), 368-389.

Rumpf, C. (2017). Decentering power in research with criminalized women: A case for photoelicitation interviewing. Sociological Focus, 50(1), 18-35. 
Sampson, R \& Laub, J. (1992). Crime and deviance in the life course. Annual Review of Sociology, 18, 63-84.

Sered, S. S. \& Norton-Hawk, M. (2014). Can't catch a break: Gender, jail, drugs, and the limits of personal responsibility. Oakland, CA: University of California Press.

Smiley, C. (2014). Existing but not living: Neo-civil death and the carceral state. $\mathrm{PhD}$ dissertation, Graduate Center, City University of New York.

Teti, M., Martin, A., Ranade, R., Massie, J. Malebranche, D., Tschann, J., \& Bowleg, L. (2011). "I'm a keep rising. I'm a keep going forward, regardless": Exploring black men's resilience amid socio-structural challenges and stressors. Qualitative Health Research, 22(4), 524-533.

Travis, J. 2009. "What Works" for successful prisoner reentry. U.S. House of Representatives Committee on Appropriations: Subcommittee on Commerce, Justice, Science, and Related Agencies. Retrieved May 26, 2014 (http://www.jjay.cuny.edu/travis congressional testimony.pdf).

Travis, J., Solomon, A. L., \& Waul, M. 2001. From prison to home: The dimensions and consequences of prisoner reentry. Washington, DC: The Urban Institute. Retrieved May 26, 2014 (http://www.urban.org/UploadedPDF/from_prison_to_home.pdf).

Turanovic, J. J., Rodriguez, N., \& Pratt, T. C. (2012). The collateral consequences of incarceration revisited: A qualitative analysis of the effects on caregivers of children of incarcerated parents. Criminology, 50(4), 913-959.

Uggen, C. (1999). Ex-offenders and the conformist alternative: A job quality model of work and crime. Social Problems, 46(1), 127-151.

Uggen, C, \& Manza, J. (2002). Democratic contraction? Political consequences of felon disenfranchisement in the United States. American Sociological Review, 67(6), 777-803.

Uggen, C., Manza, J. \& Behrens, A. (2004). Less than the average citizen: Stigma, role transition, and the civic reintegration of convicted felons: pathways to offender reintegration. In S. Maruna \& R. Immarigeon (Eds.), After crime and punishment: Pathways to offender reintegration (pp. 261-293). Cullompton, Devon, UK: Willan Publishing.

Wacquant, L. (2010). Prisoner reentry as myth and ceremony. Dialectical Anthropology, 34(4), 605-620.

Welsh, M. \& Rajah, V. (2014). Rendering invisible punishments visible: Using institutional ethnography in feminist criminology. Feminist Criminology, 9(4), 323-343. 
Werth, R. (2013). The construction and stewardship of responsible yet precarious subjects: Punitive ideology, rehabilitation, and "tough love" among parole personnel. Punishment \& Society, 15(3), 219-246.

Western, B. \& Pettit, B. (2010). Incarceration and social inequality. Daedalus, 139(3), 8-19.

Wheelock, D. (2005). Collateral consequences and racial inequality: Felon status restrictions as a system of disadvantage. Journal of Contemporary Criminal Justice, 21(1), 82-90.

Williams, Q. (2015). Returning citizens? The path from prison to politics among the formerly incarcerated. Master's thesis, Department of Sociology, Loyola University Chicago.

Quintin Williams is a Doctoral Candidate in the Department of Sociology at Loyola University Chicago. His research interests include race and reentry, crime and punishment, and social inequality.

Cesraéa Rumpf, $\mathrm{PhD}$, is an Assistant Professor in the Department of Psychology, Sociology, and Criminal Justice at Benedictine University. Her research focuses on women's incarceration and post-incarceration experiences, gendered violence, and qualitative and visual research methods. 